\title{
The Need for Inclusive Romanian Libraries
}

\author{
Daniela Popa \\ Lecturer, PhD \\ Transilvania University of Brasov \\ E-mail danapopa@unitbv.ro \\ Angela Repanovici \\ Professor, $\mathrm{PhD}$ \\ Transilvania University of Brasov \\ E-mail arepanovici@gmail.com
}

\begin{abstract}
More and more in Romania the need to have well-trained teaching and administrative staff in order to transform schools, universities and libraries into inclusive environments is felt. Often, not only the material base is missing (for example: access technologies), but a large part of staff also feels that they do not have the skills necessary to ensure effective communication with people with disabilities and their families.

This research aims to investigate the training needs of teaching staff and librarians, both in schools and universities. This article uses a mixed methods research, combining a survey based on questionnaire with one-on-one interviews. At this research 85 respondents participated, 34 of whom were professors and 51 were librarians. A majority of respondents (95\%) consider necessary to take part on courses for updating the knowledge and skills necessary for working with children/pupils/students with disabilities and their families. Also, the respondents point out the need for a team of specialists to mediate the relationships between professionals and people with special needs.
\end{abstract}

Keywords: $\quad$ special needs students; diversity; strategic planning; inclusive environment

\section{Introduction}

A permanent concern of schools and libraries is to create an inclusive environment, an environment in which diversity has expression (Jaeger\&Franklin 2017). But the road from desires to achievements is a winding one, pressed with various obstacles. The library, along with the school, has an overwhelming role in the formation and development of students and young people of all categories, especially those who come from vulnerable groups or have special needs.

An increasing number of children with special needs attend mass education. We can also observe an increasing number of young people with special needs who decide to continue their university studies. But for them, particular educational and informational support should be implemented. "Limited access to communication technologies, trained staffing, or other basic supports are common" (Mulliken\&Atkins 2009, p. 276). Public, school libraries and especially university libraries are a real support in developing the skills of those who wish to learn, regardless of age, capacity, ethnicity or other differentiation criteria.

In the specialized literature we find that there are still situations in which students with disabilities integrated in mass education are marginalized, isolated and have partial access to information (Pijl 2018). The limited access to information is due, in part, to the difficulty of entering institutions destined to culture and education or receiving personalized support for their needs. Books in special formats (e.g. Braille) are missing, access technologies are missing, audio book collections are poor or non-existent.

Pionke\&Manson (2018, p. 63) states that although many libraries are inclusive environments, however:

Revista Română de Biblioteconomie şi Ştiința Informării = Romanian Journal of Library and Information Science ISSN 2559-5490, ISSN-L 1841-1940 • Volume 15 Issue 3-4 2019 pp. 90-95 https://doi.org/10.26660/rrbsi.2019.15.34.90

This work is licensed under a Creative Commons Attribution-NonCommercial-NoDerivatives 4.0 International License 
"there continues to be a deficit in services and information for and about individuals with disabilities, especially resources on different types of disabilities grouped in the same, easily accessible, location that address various types of information including clinical, academic, assistive technologies, or popular culture".

The Romanian reality is similar to that of other countries. Often librarians express their concern about not being able to cope with the challenges posed by children and students with learning disabilities. They consider necessary to implement measures such as: "program modifications, staff training, collections and resource, and the idea of co-location" (Ross\&Akin 2002, p. 15).

Libraries and schools are institutions that rather react to social changes, to educational policy and are less proactive. An American study that measures the progress made by libraries regarding their accessibility for people with disabilities shows that, although they have much more experience on this subject, compared to our country, there are still issues that can be improved (Willis 2012). Although they meet the minimum criteria required, the issues discussed relate to the training of staff to effectively communicate with people with disabilities and to avoid their social labelling, text friendly formats, online catalogues, the use of adaptative equipment. Libraries wishing to serve persons with disabilities can begin by exploring ways to implement assistive technology (Burke 2009).

Another important aspect is the inclusion in the curriculum list of readings and the provision by the public and school libraries of those books that highlight, portray people with disabilities (Wopperer 2011). The Romanian reality shows a tendency to implement this aspect. Aside from the inspirational model that all students can find in these characters, they can develop empathy and tolerance towards people with special needs.

The vast majority of library staff training sessions can be done both at the workplace and online (Brannen et al. 2017). The main content areas aim to improve communication competences and resources training, preparing the librarian on the necessary services and equipment. A recent study proposes an inclusive library model for children with disabilities and their families (Kaeding et al. 2017). Such an institutions must focus on some essential elements such as: "collections, physical barriers (space and equipment), partnerships, programs, training and marketing" (Kaeding et al. 2017, pp. 107-108). Supporting diversity is one of the essential principles of inclusive library, a value that brings children, library students closer (Switzer 2008).

\section{Methodology}

The research investigates the training needs of teaching staff and librarians regarding their skills in working with children/pupils/students with disabilities and their families. To achieve this goal, mixed methods research was used, combining a survey based on questionnaire with one-on-one interviews. The questionnaire was built for this research and contains 10 items, of which 5 are aimed at obtaining socio-demographic data, and the following 5 are aimed at the perception of respondents about the institution in which they work. Also, 6 one-on-one interviews were conducted (two librarians, two professors from university education, one teacher from preuniversity education and a school psychologist).

"Mixed methods research is formally defined here as the class of research where the researcher mixes or combines quantitative and qualitative research techniques, methods, approaches, concepts or language into a single study" (Johnson\&Onwuegbuzie 2004, p. 17). It has been preferred to use such a research design, typical in educational research, as it allows capturing the complexity of the investigated phenomenon.

The research objectives were:

1. Identification of the degree of inclusion of the organization/institution in which the participants work (i.e., if it allows the access of persons with disabilities and if it is prepared to respond to their specific needs);

2. Analyzing the need for a training/updating course of the knowledge and skills necessary for working with children/students/students with special needs; 
3. Highlighting those competencies, skills and knowledge that should offer such a course;

4. Knowledge of the characteristics of educational and cultural context that justifies the current reality.

\subsection{Participants}

A number of 85 persons, 79 respondents to the survey and 6 respondents to the interviews, expressed their agreement to participate in this research. Before applying the research tools, each participant gave his/her informed consent to participate in the research. Subjects were explained the purpose, methods and research instruments and their rights as research participants. The completion time of the questionnaire was 5-7 minutes for each participant.

The questionnaire was applied electronically, using the Survey Monkey platform. Potential subjects received research information, informed consent, and the link to the questionnaire. Respondents from Argeș, Bucharest, Bacău, Brașov, Buzău, Galați, Iași, Ilfov, Olt, Oradea, Sibiu, Timiș, Vrancea, of whom 49 are librarians and 30 are teachers. Of the teachers, $30 \%$ are from higher education and the rest from pre-university education.

As we can see in Table 1, among the participants, 12 people were identified as having a technical training, 2 persons as having a background in the exact sciences, and $57 \%$ of the total subjects have a humanistic training. The category of $25 \%$ of the total who chose another educational profile is made up of managers, social assistants, teachers for primary education, special psychopedagogy teachers, and documentary teachers.

Table 1. The profiles of the respondents' specializations

\begin{tabular}{cccc}
\hline & & Frequency & Percent \\
\hline \multirow{3}{*}{$\begin{array}{c}\text { Specialization profile } \\
\text { of respondents }\end{array}$} & Other: & 20 & 25,3 \\
\cline { 2 - 4 } & Technical & 12 & 15,2 \\
\cline { 2 - 4 } & Exact Sciences & 2 & 2,5 \\
\cline { 2 - 4 } & Humanities & 45 & 57,0 \\
\cline { 2 - 4 } & Total & 79 & 100,0
\end{tabular}

The group of respondents includes both young and mature people. In Table 2, we notice the relative homogeneity of the lot from the point of expertise in their profession. Thus, $22.7 \%$ of the total, have accumulated maximum 15 years of professional experience, and $77.2 \%$ have over 16 years of work experience.

Table 2. The years of work experience of respondents

\begin{tabular}{llcc}
\hline & & Frequency & Percent \\
\hline \multirow{4}{*}{ Seniority } & $0-5$ years & 8 & 10,1 \\
\cline { 2 - 4 } & 6-10 years & 8 & 2,5 \\
\cline { 2 - 4 } & $11-15$ years & 61 & 10,1 \\
\cline { 2 - 4 } & Over 16 years & 79 & 77,2 \\
\cline { 2 - 4 } & Total & & 100,0
\end{tabular}

Apart from respondents described above, at the one-on-one interviews attended two librarians, two university professors, one teacher in secondary education and a school psychologist. The interviews were conducted at their places of work. The maximum duration of the interviews was 30 minutes. The interviewees have over 10 years' experience at the workplace. Aspects related to inclusive education, the rights of persons with disabilities, universal design of learning were topics 
well known to the respondents.

\section{Results}

The inclusive organization/institution has been defined as one that allows access for people with disabilities and is prepared to respond to their specific needs. The results of questionnaire-based survey show that $63.29 \%$ of all respondents believe that the organization/ institution where they work is an inclusive one and $36.71 \%$ consider that the organization/ institution (school, library) in which they work is not inclusive.

A majority of respondents $(95 \%)$ consider necessary to take part on courses for updating the knowledge and skills necessary for working with children/students/students with disabilities and their families. A significant number of respondents, representing $40 \%$ of total group, considers that psycho-pedagogical skills specific to working with students with special needs should be the focus of such a course. Participants have detailed these skills as: communication skills and networking, "about how people with disabilities should be approached", depending on their condition, the ability to adapt the didactic and library activities to the needs and characteristics of the child with disabilities, knowledge of the specific needs and modalities of action, modalities to adapt the curriculum according to the disability, classroom management (of the training process and group/ interpersonal relations) in the class with typical and disabled students.

Another group of skills that respondents seem necessary in working with people with special needs are communication, networking and organizational skills detailed as follows: communication languages, techniques for adapting the services for different categories of disabilities, interaction modalities, how to identify what the expectations of people with special needs are from the library, information on appropriate behaviour, "to be able to help them feel comfortable next to other colleagues", organizational and digital competencies, reading psychology, bibliotherapy, communication with students' parents with special needs.

The participants identified a third category, materialized in the need to know those specific services for people with disabilities: techniques for adapting the services to different categories of disabilities, things needed in order to be able to work with people with special needs, possible applications that can be used for this category of people, software for adapting existing materials in libraries for people with special needs, access and training technologies to use these mediation tools.

Also, a large part of the subjects emphasized the necessity to train/develop the attitudes needed to work with people with special needs. Thus, the following training needs were highlighted: skills development and knowledge of methods in order to communicate effectively and interact beneficially to people with special needs, understanding, empathy, patience, tolerance, good observation, the desire to change the current attitude of rejection or avoidance, "to learn to know their needs; learn to make them understand that special needs are not necessarily an obstacle in personal development".

In the section for answers, comments and suggestions of respondents, they have pointed out the need for a team of specialists to mediate the relationships between professionals and people with special needs, as well as the need for continuous training courses for professionals in the educational and cultural fields in order to meet the needs of all children, pupils and students, regardless of their limitations.

From the analysis of the information revealed by one-on-one interviews, we have identified that the measures related to the access of persons with motor or visual disabilities in the institutions are rather under development or in the process of being finalized. Very few institutions have access ramps, elevators or automatic doors. Also, indicators in Braille or accompanying persons, specially designated or a guiding application of the institution or organization seem to be elements of a very distant future.

To a large extent, spaces for education and culture are not adapted for people with special mobility needs. The furniture is not adapted to them, some spaces being totally inaccessible. Access technologies are missing, search engines of information resources are not adapted to people with 
disabilities, audio-book collections are limited or missing, educational materials are mostly old and limited.

Respondents also point to the need for a team of specialists to mediate the relationships between professionals and people with special needs and to facilitate communication and cooperation between librarians, teachers on the one hand, and persons with special needs and their families, on the other. The respondents consider that the existence within the organizational structure of the institution they represent by, of at least one person whose training profile would include skills in the field of special psycho-pedagogy, would represent progress towards an inclusive environment.

\section{Discussion and conclusions}

In this research, answers were obtained related to the identification of the degree of inclusion of organization/institution in which the participants work (if it allows the access of people with disabilities and if it is prepared to respond to their specific needs). Although at the declarative level, the analyzed institutions (schools and libraries) try to become inclusive, there are still many steps needed to reach a satisfactory level of adaptation for people with special needs.

The analysis of the training needs revealed the need to implement at least one training course/to update the knowledge and skills necessary for working with children/pupils/students with special needs, which will cover all the components of a competence (information, skills and attitudes). An overwhelming majority, representing $95 \%$ of the total number of respondents, considers that such educational steps are necessary.

The research also aims to highlight those skills, abilities and knowledge that should be offered by such a course. Following the analysis of the results obtained, they are: the psycho-pedagogical skills specific to working with students with special needs, communication, relational and organizational skills, knowledge of those services, specific techniques for people with disabilities and the need to train/develop the necessary attitudes in working with people with special needs.

Last but not least, the research aimed to identify the characteristics of the educational and cultural context that justify the current reality. Often, the respondents considered that the extremely low level of real inclusion is due to the lack of funds but also to the poor educational preparation to provide an adequate and stimulating environment for all people, regardless of their needs.

\section{References}

Brannen, M.H., Milewski, S. and Mack, T. (2017) Providing Staff Training and Programming to Support People with Disabilities: An Academic Library Case Study, Public Services Quarterly, 13 (2) pp. 61-77, available: https://doi.org/10.1080/15228959.2017.1298491.

Burke, S.K. (2009) Perceptions of Public Library Accessibility for People with Disabilities, The Reference Librarian, 50(1) pp. 43-54, https://oi.org/10.1080/02763870802546381.

Jaeger, P.T. and Franklin, R.E. (2017) The virtuous circle: increasing diversity in LIS faculties to create more inclusive library services and outreach, Education Libraries, 30(1) pp. 20-26, available: https://doi.org/10.26443/el.v30i1.233.

Johnson, R.B. and Onwuegbuzie, A.J. (2004) Mixed methods research: A research paradigm whose time has come, Educational Researcher, 33(7) pp. 14-26, available: https:// doi.org/10.3102/0013189x033007014.

Kaeding, J., Velasquez, D.L. and Price, D. (2017) Public Libraries and Access for Children with Disabilities and Their Families: A Proposed Inclusive Library Model, Journal of the Australian Library and Information Association, 66(2) pp. 96-115, available: https:// doi.org/10.1080/24750158.2017.1298399.

Love, J.B. (2001) The assessment of diversity initiatives in academic libraries. Journal of library administration, 33(1-2) pp. 73-103, available: https://www.tandfonline.com/doi/abs/10.1300/ $\underline{\mathrm{J} 111 \mathrm{v} 33 \mathrm{n} 01 \text { 07? journalCode }=\text { wjla20 }}$ 
Mulliken, A. and Atkins, A. (2009) Academic Library Services for Users with Developmental Disabilities, The Reference Librarian, 50(3) pp. 276-287, available: https:// doi.org/10.1080/02763870902873461.

Pijl, S.J. (2018) The resources for regular schools with special needs students: An international perspective, in Clark, C., Dyson, A. and Millward, A. (eds.), Towards Inclusive Schools? New York: Routledge, pp. 54-62.

Pionke, J.J. and Manson, J. (2018) Creating Disability LibGuides with Accessibility in Mind, Journal of Web Librarianship, 12(1) pp. 63-79, available: https:// doi.org/10.1080/19322909.2017.1396277.

Ross, V. and Akin, L. (2002) Children with Learning Disabilities and Public Libraries: An ESurvey of Services, Programs, Resources and Training, Public Library Quarterly, 21(4) pp. 9-18, available: https://doi.org/10.1300/J118v21n04_03.

Switzer, A.T. (2008) Redefining diversity: Creating an inclusive academic library through diversity initiatives, College \& Undergraduate Libraries, 15(3) pp. 280-300, available: https:// doi.org/10.1080/10691310802258182.

Willis, C.A. (2012) Library Services for Persons with Disabilities: Twentieth Anniversary Update, Medical Reference Services Quarterly, 31(1) pp. 92-104, available: https:// doi.org/10.1080/02763869.2012.641855.

Wopperer, E. (2011) Inclusive literature in the library and the classroom, Knowledge Quest, 39(3) pp. 26-34, available: https://search.proquest.com/docview/856360544?pq-origsite=gscholar [accessed 16 September 2019]. 